\title{
Pedagogical Techniques to Promote Development of Graduate Engineering Students as Disciplinary Writers
}

Dr. Sarah Lyn Gassman, University of South Carolina

Dr. Sarah Gassman is an Associate Professor in the Department of Civil and Environmental Engineering Department at the University of South Carolina

Dr. Michelle A Maher, University of South Carolina

Dr. Briana Timmerman, UVA Curry School of Education, Charlottesville VA

Dr. Charles E. Pierce, University of South Carolina 


\title{
Pedagogical Techniques to Promote Development of Graduate Engineering Students as Disciplinary Writers
}

\begin{abstract}
As demands for research productivity increase, faculty, particularly untenured junior faculty, must efficiently expedite the development of their graduate students' disciplinary writing skills. In response to this need, a semester-long graduate course was offered within the Department of Civil and Environmental Engineering at the University of South Carolina for the first time in 2012. The primary course outcome was for each student to prepare a manuscript ready, or near ready, for submission to a peer reviewed engineering journal at semester's end. To facilitate this outcome, course content addressed the purpose of and information included in each section of a standard engineering research article. Emphasis was placed on the appropriate use of primary literature and effective critique of peer writing. In an assessment administered at course initiation, students rated their comfort level with disciplinary writing and reassessed their comfort level upon course conclusion. Analysis of pre- and post-course change in levels of selfreported confidence as a disciplinary writer revealed a marked average increase. In addition, students identified (though free recall) pedagogical techniques perceived to best facilitate their development as writers. The three most identified techniques were Manuscript Rubric, Conceptual Mapping, and Writing Goal Accountability. Rationale for and demonstration of each of these techniques is offered in this paper as guidance to faculty who mentor their own students' development as disciplinary writers.
\end{abstract}

\section{Introduction}

Disciplinary writing in the form of contributions to grant proposals, peer-reviewed journal publications, and conference papers is a natural outcome of gradate engineering students' research activities and vital to the research productivity of these students' faculty advisors. However, while students may possess content knowledge and technical expertise, many enter graduate programs with limited understanding of the disciplinary writing and publication processes. Graduate students typically learn about these processes through intensive hands-on guidance from their faculty mentor ${ }^{9,12}$. Yet, while graduate mentoring is prized among many engineering faculty, individual guidance in the basic structure of and process for generating disciplinary writing is laborious and can greatly slow faculty research productivity.

Other challenges await faculty who seek to support their students' development as disciplinary writers. Faculty may lack appropriate pedagogical training, as many attended research-intensive doctoral programs ${ }^{10,16}$. They may struggle to translate their own expertise as a writer into pedagogical guidance that students can follow, as writing expertise is often automated ${ }^{1}$. Candid discussions about pedagogical practices supporting students as disciplinary writers are usually rare within departments, institutions, and even disciplines. Finally, while institutions of higher education may expect faculty to facilitate students' scholarly writing and include it within faculty reward structures, sustained institutional-level support for student disciplinary writing is usually quite limited. 
In response to the above challenges, a semester-long graduate course was offered within the Department of Civil and Environmental Engineering at the University of South Carolina for the first time in 2012. The primary course outcome was for each student to prepare a manuscript ready, or near ready, for submission to a peer reviewed engineering journal at semester's end, and several pedagogical techniques were used in support of this outcome. In an assessment administered at course initiation, students $(n=22)$ rated their comfort level with disciplinary writing and reassessed their comfort level upon course conclusion. In addition, students identified (though free recall) pedagogical techniques perceived to best facilitate their development as writers. Analysis of pre- and post-course change in levels of self-reported confidence as a disciplinary writer revealed a marked average increase. As well, student identified the pedagogical techniques they perceived best facilitated their development as a disciplinary writer. This paper identifies these techniques and provides guidance on their use.

\section{Course and Student Overview}

The course, “Writing for Publication”, was offered to graduate students on a voluntary basis and immediately filled to capacity. The course met weekly for 1.5 hours, with course sessions structured as writing workshops supplemented with presentations and group discussions. The course had three instructors: one was the instructor of record from the Department of Civil and Environmental Engineering and the other two represented the University's College of Education and The Graduate School. Several additional faculty from the Civil and Environmental Engineering Department attended the course throughout the semester. Grading was Pass/Fail and based on attendance and class participation. The following learning objectives were set forth:

Students will demonstrate effective knowledge of

1. Common characteristics of primary literature and rationale for use;

2. How to read and synthesize primary literature like an engineer or scientist;

3. Information in and purpose of each research article section and how to evaluate the quality of each section;

4. Correct use of citations and references to others' scholarly work; and

5. How to give, receive, and use constructive peer feedback on written materials.

Twenty-two graduate students (1 master's degree, 21 doctoral) enrolled in the course, representing the research efforts of nine separate civil engineering professors across four diverse areas of civil engineering (environmental engineering, structural engineering, transportation engineering, and water resources engineering). Mirroring the departments' graduate student population, students in this course were drawn from a broad band of nationalities and demonstrated varying degrees of proficiency with the English language. Six students (27\%) were female, with the smaller number of females than males reflecting the reality that females are underrepresented in STEM disciplines ${ }^{8}$.

At semester's start, students provided self-descriptions of prior writing activities. Responses revealed that 13 students (59\%) had authored or coauthored a published or submitted scholarly paper, while 14 (64\%) had authored or coauthored a conference paper. Six (27\%) reported they had never contributed to either a published/submitted paper or a conference paper. Most course 
participants had completed several years of graduate work, while a few were just beginning their programs.

As noted above, the primary course outcome was for each student to prepare a manuscript ready, or near ready, for submission to a peer reviewed engineering journal at semester's end. To facilitate this outcome, course content addressed the purpose of and information included in each section of a standard engineering research article. Course activities included locating relevant primary literature, creating literature concept maps to organize disciplinary knowledge and identify areas for investigation, iteratively honing writing skills through the creation of successively more advanced manuscript drafts, creating and presenting meaningful figures, and applying rubrics to solicit and provide valuable peer-to-peer feedback. Emphasis was placed on the appropriate use of primary literature and effective critique of peer writing to heighten students' recognition that through writing for publication they join their discipline's ongoing scholarly dialogue. A range of pedagogical techniques were used to facilitate course outcomes.

\section{Pedagogical Techniques Perceived to Facilitate Writing Development}

Upon course conclusion, students identified (though free recall) pedagogical techniques perceived to best facilitate their development as writers. Tabulation of these responses identified the use of three techniques: Manuscript Rubric, Conceptual Mapping, and Writing Goal Accountability. For each technique, a definition and rationale for use is provided and followed by a description of its use in the Writing for Publication course. Guidance on implementation is next offered to faculty who wish to reproduce the technique's use in mentoring their own students’ development as disciplinary writers.

\section{Manuscript Rubric}

Definition and Rationale for Use: A rubric articulates in writing the criteria used to evaluate a work product $^{18}$. A key characteristic of a rubric is that it makes these evaluative criteria explicit. In mentoring students' development as disciplinary writers, making explicit the criteria of 'outstanding' disciplinary writing is essential ${ }^{15}$, as disciplines vary widely in how written claims about knowledge are presented ${ }^{3}$. Further, within each discipline, sub disciplines communicate using specialized knowledge and language ${ }^{7}$. This range of 'insider information' can prove daunting for a novice writer. However, a carefully constructed rubric that explicitly spells out the traits of 'outstanding' disciplinary writing can guide a novice writer before and as they write.

Description of Use: Figure 1 displays a portion of the Universal Lab Rubric (URL) ${ }^{17}$, a tool designed to assess the quality of scientific writing. Students were provided with the ULR and encouraged to refer to it as they individually drafted each section of their manuscript. In class, student pairs exchanged individually written work and each student applied the rubric to their partner's writing sample. During this process, they voiced out loud their thoughts and reactions about their peer's writing. Specifically, students identified parts of the writing that were clear and fully developed, in keeping with the rubric, and parts of the writing where improvement was needed - and ideas of how to implement that improvement. Students have been noted to express concerns about offering meaningful feedback to peers in light of their own lack of writing experience or confidence ${ }^{5}$. However, providing students with a rubric, such as the URL, that 
makes evaluative criteria explicit seemed to allay these concerns.

Figure 1. Portion of the Universal Lab Rubric

\begin{tabular}{l} 
Introduction: Context \\
\begin{tabular}{|l|l|l|l|l|}
\hline & Not Addressed & Novice & Intermediate & Proficient \\
\hline $\begin{array}{l}\text { Demonstrates } \\
\text { understanding of the } \\
\text { "big picture"; Why } \\
\text { is this question } \\
\text { important to the } \\
\text { field? }\end{array}$ & $\begin{array}{l}\text { The importance } \\
\text { of the question is } \\
\text { not addressed. }\end{array}$ & $\begin{array}{l}\text { Writer provides a } \\
\text { vague rationale } \\
\text { for the } \\
\text { importance of the } \\
\text { question. }\end{array}$ & $\begin{array}{l}\text { Writer provides } \\
\text { an explanation } \\
\text { of why others } \\
\text { would find this } \\
\text { important. }\end{array}$ & $\begin{array}{l}\text { Clear sense } \\
\text { of why this } \\
\text { knowledge } \\
\text { may be } \\
\text { important } \\
\text { to field. }\end{array}$ \\
\hline
\end{tabular} \\
\hline
\end{tabular}

Practice and Suggested Facilitation: The following guidance is offered to faculty mentors to create a manuscript rubric for their students:

(1) First review submission guidelines of reputable journals in your area; they often provide a broad checklist of 'must have' manuscript traits that can be used as a starting point. Also identify articles written at a proficient, intermediate, or novice level.

(2) In concert with your student(s), review the articles. In each article section, identify the traits or characteristics that are definitive of this genre (e.g., across articles, what does each one include in the Introduction section?)

(3) For each trait or characteristic, consider how it would appear in the article if it was presented at a proficient, intermediate, or novice level (and note when it is missing).

(4) Strive to clearly articulate to your students why you consider each trait or characteristic to be definitive of each article section, and why/how you made evaluative judgments about how it is presented to the reader.

(5) Revise your developing manuscript rubric with your students throughout the writing process, using it as a tool to both begin discussion about 'proficient' disciplinary writing and to evaluate the students' writing that is in progress.

\section{Concept Mapping}

Definition and Rationale for Use: Concept maps are "drawings or diagrams showing mental connections that students make between a major concept ... and other concepts they have learned"2. The use of concept maps can be particularly useful for assisting students as they incorporate new knowledge into their existing mental maps or schemas. Novice disciplinary writers gather a wealth of new knowledge as they review relevant literature. However, they may not know how to consolidate and integrate this knowledge in a way that allows them to see both the 'big picture' of their area of inquiry, as well as the gaps in existing knowledge. Constructing 
a concept map of the articles they locate in their literature review will allow students to do both. Additionally, it can provide a sense of order and command over what might at first seem like a vast and overwhelming domain of disconnected articles.

Description of Use: Figure 2 shows a concept map created by one of the authors. This map was distributed to the students with a description of how the map was created to link different article citations and collections of similar articles to interconnected concepts.

Students were then asked to create their own concept map, which at first might be very simple, consisting of only a few concepts and citations. Students were particularly enthusiastic about this technique when they each received a large blank piece of paper, which served as a canvas or a big white board. Students were encouraged to bring their maps to class on several occasions, showing their peers and the instructors how they had modified their map over the span of several weeks. Several students used their concept maps to begin a dialogue with their faculty mentors, showing them how they visualized the interconnections among the literature they had read and how the map in total informed the rest of their manuscript. In fact, some students prominently displayed their maps by their desks or in other places within research labs to tangibly display their developing thinking about their line of inquiry.

Figure 2. Concept Map of a Literature Review

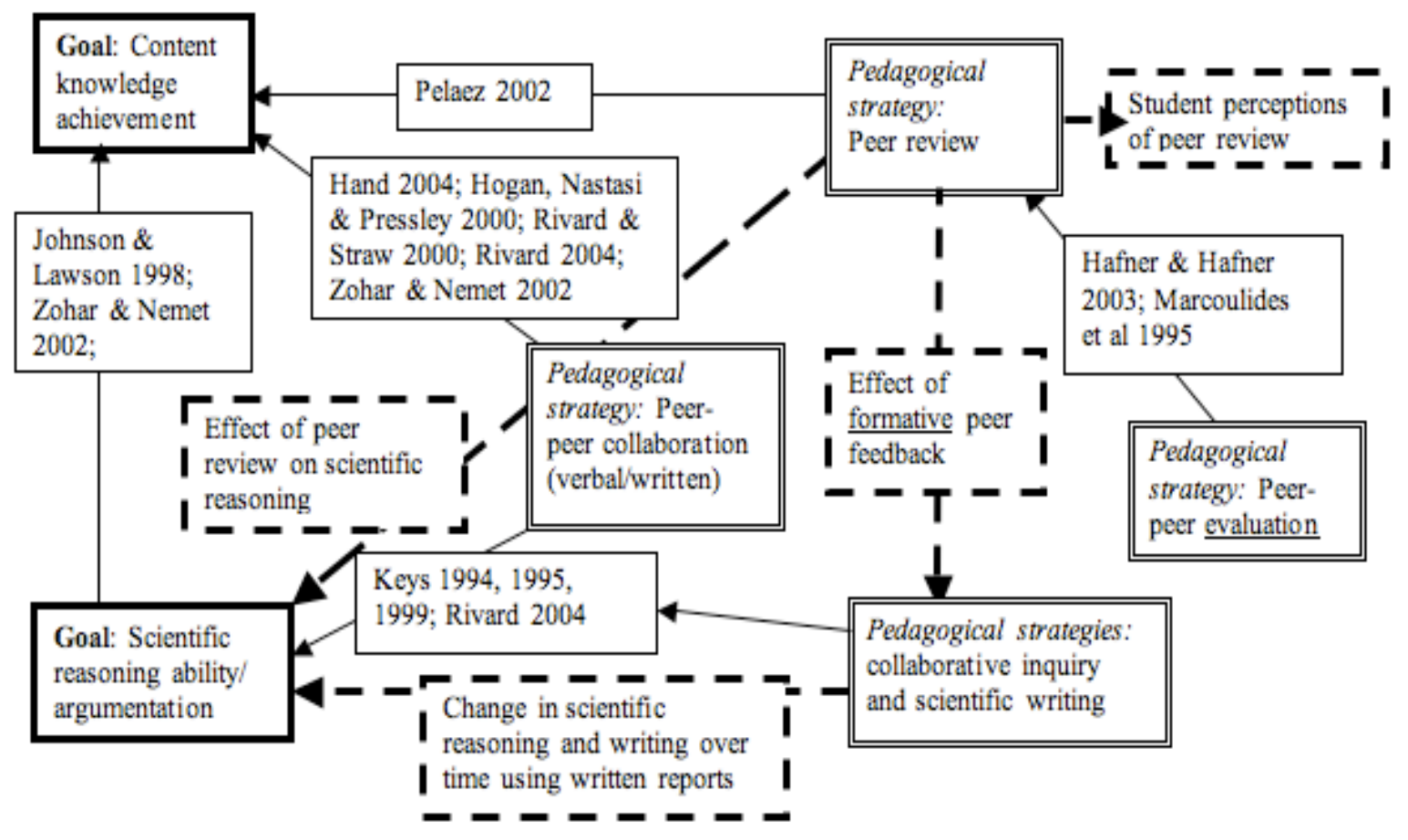


Practice and Suggested Facilitation: Students should begin with large blank sheets of paper, which can be easily found at any office supply store (large flip chart pads or butcher paper rolls). Students should also use pencils so they can easily make changes to their map. With your student, identify the concepts or ideas that are fundamentally guiding the student's search for relevant literature. Then, ask your student to determine the relationships between these concepts. For example, hierarchical relationships may exist in which some concepts serve as a broad category for a series of more limited concepts. Be aware that students may make several 'false starts' as they grapple with determining which concepts are relevant and then identify the relationships between these concepts (this is why the availability of more than one large sheet of paper can be soothing). As their understanding of the concepts and their interrelationships begins to solidify, students can add citations to their map to indicate articles that support, complicate, or even contradict the emerging understandings of how concepts 'fit together' to form the larger picture. Students should be encouraged to remain cognitively flexible as they construct and reconstruct their map. As their understanding of the area advances, they will likely make substantial changes in their map.

\section{Writing Goal Accountability}

Definition and Rationale for Use: Novice disciplinary writers (like many writers) can struggle to make consistent writing progress for a myriad of reasons. Good intentions to write can be sidetracked by competing obligations and pressing deadlines ${ }^{11}$. For students enrolled in classes, serving as teaching or laboratory assistants, and perhaps trying to balance family or other off campus obligations, finding time, structure, and motivation to write can prove challenging. In response, they may succumb to unhealthy habit of 'binge writing', mistaking believing that they will be more creative and productive if they write sporadically in bursts that lead to exhaustion ${ }^{4}$. A simple way to create effective writing habits and ensure steady progress is to set writing goals.

A goal is simply an articulated desired end-state. Goal setting has received intense scholarly attention, particularly in the area of work motivation ${ }^{6}$. Research on goal-setting has repeatedly confirmed that goals that are specific, measureable, and observable (e.g., 'write one page a day') produce higher performance than ambiguous goals (e.g., 'do your best') ${ }^{13,14}$. As anyone who has tried to break a bad habit or ingrain a new habit can attest, telling others about your goal makes you much more likely to keep it.

Description of Use: Goal-setting, combined with peer accountability, was used in the course to encourage students to make consistent, specific, measureable, and observable writing progress. Students were divided into three- or four-person teams. In advance, instructors identified a team leader based on extent of academic writing experience.

Team membership was purposely mixed across research laboratories and engineering sub disciplines to heighten students' sense of accountability. Additionally, in the laboratory sciences, students often collaborate in narrow subject areas, and a peer may tacitly and even unknowingly supplement his or her lab mate’s writing with insider knowledge unavailable to others. Therefore, each student had the 'fresh eyes' of peers outside their laboratories and sub disciplines to review their work. 
Each week, team members discussed each team member's writing progress. To facilitate this discussion, each week a 'team productivity form' (partly shown in Figure 3 below) was distributed and team members completed it in class. Copies of this form were made during a short class break so that each team member had a copy of what he or she had promised to accomplish by the following week, as well as what each other team member had promised to accomplish. Care was taken to emphasize the importance not only of what each student would be held accountable to accomplish, but also what current strength their writing demonstrated that could serve as a foundation on which to build writing progress.

\section{Figure 3. Team Productivity Form}

Team Leader Name:

Team Members’ Names:

\begin{tabular}{|l|l|l|}
\hline Team Member Name & Strength to Build On & Will Do By [date] \\
\hline & & \\
& & \\
\hline
\end{tabular}

Practice and Suggested Facilitation for Mentors and Students: Asking students to work in teams was a byproduct of the class size. If, for example, a faculty and student are coauthoring a manuscript, they can easily use the idea of goal-setting and accountability by simply making an action item list that each will promise, as a minimum, to accomplish by the next meeting. The difficult part is to hold each accountable for progress and not succumb to temptation to say, 'This week was so busy that neither of us could accomplish our goals.' In this case, the burden probably falls upon the faculty mentor to model the habit of setting - and meeting - writing goals.

\section{Outcome}

As part of an assessment administered at the start of the course, the students $(n=22)$ were asked to rate their comfort level with professional writing on a scale of 1 (very low) to 10 (very high). The assessment was re-administered upon course conclusion. Analysis of pre-course and postcourse change in levels of self-reported confidence as a disciplinary writer revealed an overall increase in self-reported confidence as shown in Figure 4. The average self-reported confidence increased from 4.8 to 6.4; the median increased from 5 to 7 and the mode increased from 6 to 7.

Four students provided post-confidence scores lower than their initial confidence scores. A review of the explanation provided by each student showed that three found that additional writing experience over the semester revealed to them that disciplinary writing was more complex than they first envisioned. One indicated that he had 'no results worth showing,' suggesting he interpreted the question based on his comfort level in reporting a particular project, not his overall comfort level with writing. 


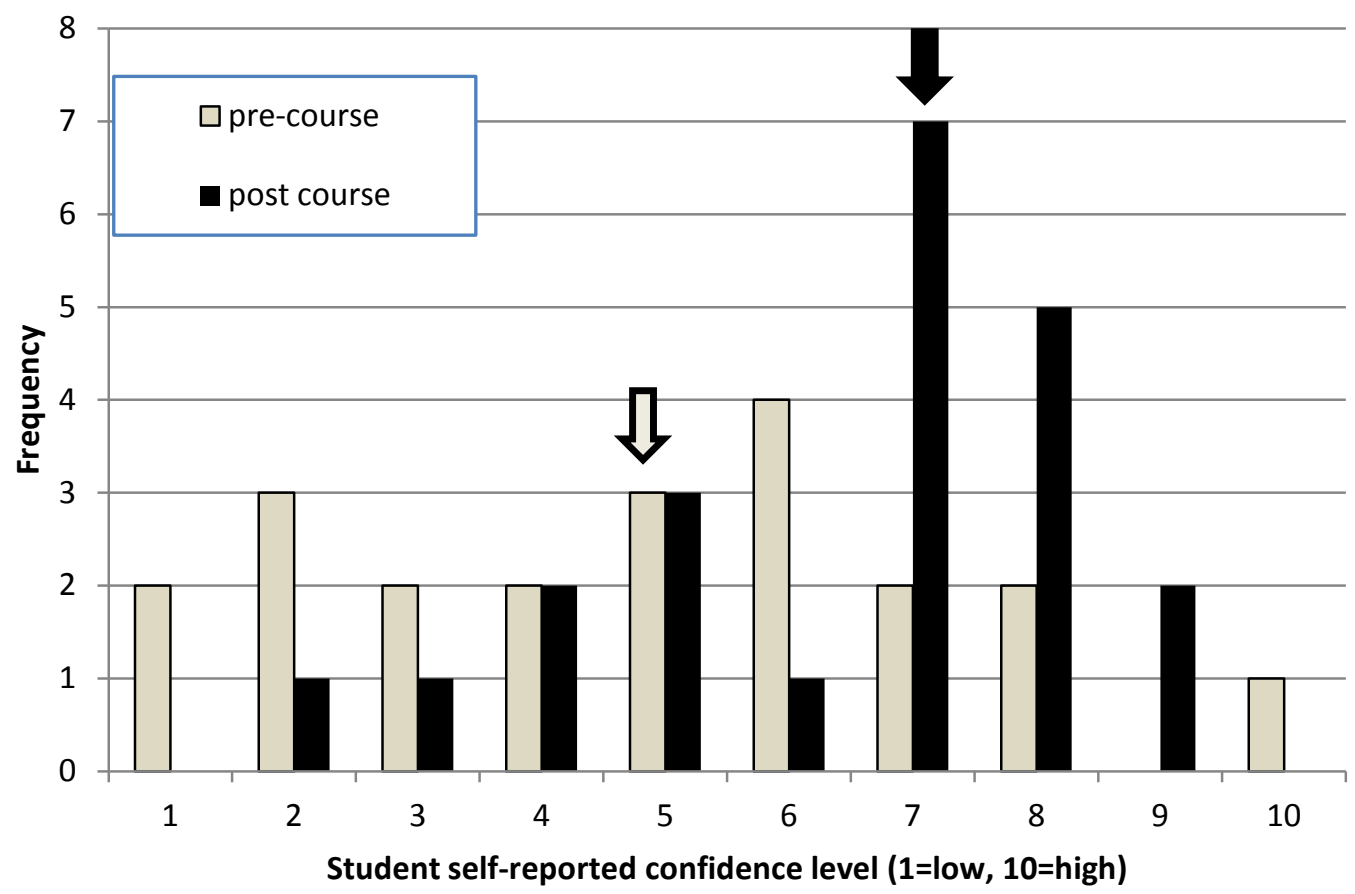

Figure 4. Change in confidence levels for disciplinary writing reported by students over the course of the semester $(n=22)$

To capture the perspectives of students' faculty advisors regarding course outcomes, each of the nine faculty who had students enrolled in the course were invited to respond to a short survey upon course conclusion. Survey questions addressed perceived changes in student writing ability, frequency of faculty-student discussion of course activities, and, more broadly, disciplinary writing as compared to previous semesters. Seven of nine faculty participated in the survey, and their responses were analyzed for further insight into the pedagogical techniques perceived to be most beneficial to the development of disciplinary writing.

Faculty advisors perceived that course participation facilitated most (but not all) students' development as writers. Most described development in broad terms (e.g., "I have seen that his technical writing has improved significantly”). Of faculty who noted a specific area of improvement, comments associated with paper structure/organization were common:

All three students appear to have a better understanding of how a paper should be structured and how to write well organized paragraphs. For example, I recently reviewed a draft of a manuscript that [student name] is working on and it was much better than writing I have seen from him in the past.

Her ability to write an outline has improved tremendously, as has her organization of the introduction

Yes, I have asked both students about the [course] activities. They mentioned that they enjoyed looking at the different parts of a paper and found it very helpful. 
However, this was not the case for all students:

She has a very good understanding of the material but still has difficulties in organizing a logical structure for a paper.

Faculty responses suggested that faculty and students did discuss course activities as they collaborated on disciplinary writing. The concept mapping was referenced in two faculty responses:

They [students] did mention that you went over how to pull literature together with little bubble diagrams, and they thought that was very helpful, so hopefully that is something that we can use in the near future in some of our publications, and I just mention it to you because they mentioned that that was very helpful.

They [students] both really liked the concept map activity. I see this reflected in their outlines (they now show me diagrams!).

However, concept mapping was the only pedagogical technique faculty mentioned specifically. More common were references to a broad range of tactics:

I noted the fact that he [student] recalls some of the concepts/tips that were discussed in class when he and I talk about his paper...I feel that some of these concepts/tips resurface when he actually faces a relevant example or case.

The above suggests that overall faculty advisors perceived that course participation benefited most students. However, as we noted earlier, students entered the class with various levels of familiarity with disciplinary writing, and it is quite likely that not every technique was equally beneficial to every students' development as a writer. The current effort is exploratory in nature; future research would benefit from a more fine-grained analysis of the applicability of pedagogical techniques to differing levels of familiarity with disciplinary writing.

\section{Summary}

This paper presented an overview of three pedagogical techniques perceived to promote the development of scholarly writing in graduate students in the Department of Civil and Environmental Engineering at the University of South Carolina. Through use of Manuscript Rubrics, Conceptual Mapping, and Writing Goal Accountability, students learned to efficiently locate relevant primary literature, create literature concept maps to organize disciplinary knowledge and identify areas for investigation, iteratively hone writing skills through the creation of successively more advanced manuscript drafts, and apply rubrics to solicit and provide valuable peer-to-peer feedback. It is hoped that the information offered can serve as a guide to those who mentor their own students’ development as disciplinary writers. 


\section{Bibliography}

1. Aitchison, C., Kamler, B., \& Lee, A. (2010). Introduction: Why publishing pedagogies? In C. Aitchison, B. Kamler, B., \& A. Lee, (Eds.). Publishing Pedagogies for the Doctorate and Beyond (pp. 1 - 11). New York, NY: Routledge.

2. Angelo, T. A., \& Cross, K. P. (1993). Classroom assessment techniques: A handbook for college teachers (2nd ed.). San Francisco, CA: Jossey-Bass.

3. Becher, T., \& Trowler, P. R. (2001). Academic tribes and territories: Intellectual enquiry and the culture of the disciplines (2nd ed.). Philadelphia, PA: Open University Press.

4. Boice, R. (1997). Which is more productive, writing in binge patterns of creative illness or in moderation? Written Communication, 14(4), 435 - 459.

5. Caffarella, R. S., \& Barnett, B. G. (2000). Teaching doctoral students to become scholarly writers: The importance of giving and receiving critiques. Studies in Higher Education, 25(1), 39 - 52.

6. Dipboye, R. L., Smith, C. S., \& Howell, W. C. (1994). Understanding industrial organizational psychology: An integrated approach. Fort Worth, TX: Harcourt Brace College Publishers.

7. Harrison, T. M., \& Stephen, T. D. (1995). The electronic journal as the heart of an online scholarly community. Library Trends 43(4), $592-608$.

8. Hill, C., Corbett, C., \& St. Rose, A (2010). Why so few? Women in Science, Technology, Engineering and Mathematics. Sponsored by the American Association of University Women, http://www.aauw.org/learn/research/upload/whysofew.pdf

9. Hunter, A.-B., Laursen, S. L., \& Seymour, E. (2007). Becoming a scientist: The role of undergraduate research in students' cognitive, personal, and professional development. Science Education, 91(1), 36 - 74.

10. Johnson, W. (2002). The intentional mentor: strategies and guidelines for the practice of mentoring. Professional Psychology: Research and Practice, 33(1), 88 - 96.

11. Johnson, W. B., \& Mullen, C. A. (2007). Write to the top! How to become a prolific academic. New York, NY: Palgrave Macmillan.

12. Kamler, B. (2008). Rethinking doctoral publication practices: Writing from and beyond the thesis. Studies in Higher Education, 33(3), 284 - 294.

13. Latham, G. P., Mitchell, T., \& Dossett, D. (1978). Importance of participative goal setting and anticipated rewards on goal difficulty and job performance. Journal of Applied Psychology, 63(2), 163 - 171.

14. Latham, G. P., \& Steele, T. (1983). The motivational effects of participation versus goal setting on performance. Academy of Management Journal, 26(3), 406 - 417.

15. Lovitts, B. (2007). Making the implicit explicit: Creating performance expectations for the dissertation. Sterling, VA: Stylus.

16. Starke-Meyerring, D. \& Paré, A. (2011, April). Perceptions and practices of writing in doctoral education: Consequences for students and supervisors. Paper presentation at the meeting of the American Educational Research Association, New Orleans, LA.

17. Timmerman, B. (2008). Peer review of an undergraduate biology curriculum: Effects on students' scientific reasoning, writing, and attitudes. (Doctoral dissertation, Curtin University of Technology, 2008). Australasian Digital Thesis, PID 18880.

18. Walvoord, B. E. (2004). Assessment clear and simple: A practical guide for institutions, departments, and general education. San Francisco, CA: Jossey-Bass. 